\section{Cost of Working}

A DETAILED study of the continually increasing cost of scientific work at several scientific laboratories, some public and some at universities, has now been published by the secretariat of the Council for Scientific Policy. The document, The Sophistication Factor in Science Expenditure (HMSO, 6s.) is the first of a series of studies commissioned by the council. Although the study seems to have shown that the variation of the rate of increased costs from one kind of establishment to another is far too great for there to be a rule of thumb applicable right across the board, with the result that the making of science policy cannot be left to men with slide rules, the analysis of expenditure which makes up the bread and butter of the report will certainly provide the heads of university departments with a useful yardstick for deciding whether they are spending too much-or too little.

The study has been concerned with a total of sixteen laboratories-nine research stations operated by the Ministry of Technology, the National Institute for Medical Research, the Rothamsted Experimental Station, the Atomic Energy Research Establishment at Harwell, the Central Veterinary Laboratory of the Ministry of Agriculture, the chemistry department at one university and the geology and zoology departments at another. The study begins by pointing out how difficult it must be to disentangle the true cost of increasing sophistication of equipment used in research from other causes of variation from one year to another - changes in the proportions of staff of various grades, natural growth and even such phenomena as inflation.

To allow for these and other factors contributing towards the total cost of a laboratory, the study begins with the statement

$$
F / N=B+W+A
$$

where $F$ is the annual budget, $N$ the number of scientific researchers, and $B, W$ and $A$ the cost per individual researcher of buildings, wages and apparatus respectively. One cause of increasing costs from year to year is the "desire of workers to be better accommodated" as well as the usually increased cost of housing complicated equipment. It must also be reckoned that the salary bill of a predominantly youthful establishment will tend to rise quickly because of the effects of built-in salary increments. For each of the three terms on the right-hand side of this equation, the study has assumed a separate sophistication factor. The last of the three terms, for example, is written as

$$
A=A_{0} I_{\Lambda} R_{A}
$$

where $A_{0}$ is the cost of apparatus per year per worker at the beginning of some period, $I_{A}$ is a factor which represents growth due to monetary inflation and $R_{A}$ is the sophistication factor representing the increasing complexity of scientific equipment.

The chief conclusion of the report is that the increasing cost of equipment is the principal cause of rising budgets in the universities and the public laboratories. For institutions in which exceptional considerations do not inflate costs unpredictably, and where there is no natural growth, the cost of research (for each scientifically qualified man and woman) may be expected to increase by between 2 and 5 per cent a year. The report emphasizes that this range of figures is merely a pair of brackets, and that some of the laboratories included in the survey have revealed rates of growth outside these limits.

Universities seem to have experienced the most rapid increase of growth in the cost of equipment, at least if the three university departments included in the survey are a reliable guide. For one chemistry department, for example, the staff grew at $7 \cdot 2 \pm 0 \cdot 4$ per cent a year during the 8 years from 1958, but the cost of major equipment (each item exceeding $£ 100$ ) increased by an average of 27 per cent a year during the same period. The corresponding figures for the public laboratories range between essentially zero (for the National Engineering Laboratory) to 27 per cent (for the National Institute for Medical Research). The rate of growth of expenditure on major items of equipment in the zoology department of the second university worked out at 8.9 per cent, but the geology department had increased its budget for major items of equipment by 25 per cent a year over the same period. These figures are at current prices-in other words, they are not corrected for inflation.

The correction for inflation necessarily entails that the survey should rely on published information about the general increase of costs in the construction industry, for example. The average annual increase of construction costs, for example, was taken as $2 \cdot 3$ per cent. It is calculated, on the basis of pay scales in the scientific Civil Service, that the inflation of salaries during the period $1958-65$ worked out at $6 \cdot 5 \pm 0.5$ per cent a year. At the same time, the effect of inflation on prices of equipment and machinery seems to have increased by between $3 \cdot 0$ and $3 \cdot 5$ per cent a year. These figures are intended merely to represent increases of money costs arising from monetary inflation. They are, in other words, the basis of the corrections which must be applied to the annual increase of the budget of a laboratory before the true cost of sophistication can be calculated. It is nevertheless interesting and important that the buoyant trend of scientific salaries should have been so conspicuous in the past few years.

When inflation is allowed for, the increasing sophistication of the scientific labour force, chiefly expressed by the tendency for the comparative numbers of supporting staff to increase, seems to have varied widely from one laboratory to another, but to have been not too different from 1 per cent a year. According to the report of the survey, the effect on real costs arising from the way in which a youthful labour force wins rapidly increasing increments is more important, and may account for an annual increase of real costs of about 2.5 per cent a year.

The report emphasizes that this conclusion is tentative, as is the statement that "such evidence as there is suggests a sophistication factor of 2.5 per cent a year for construction costs". Minor items of equipment are considered to cost an extra $3 \cdot 0 \pm 1 \cdot 0$ per cent a year in real terms, but the secretariat of the Science Research Council has shrunk altogether from attempting to define a sophistication factor for major items of equipment. In the period covered by the review, 
expenditure under this heading seems to have varied markedly from one laboratory to another. Where the rate of expenditure on major items of equipment seems to have been about $£ 100$ per head per year, the rate of spending for major equipment may have been as much as 23 per cent. Where expenditure worked out at three times as much, however, the annual increase of expenditure might typically be about 9 per cent a year.

Although the authors of the report have been quite properly concerned with the way in which the changing character of scientific research is likely to bring in its train increases of costs, it is inevitable that those who read the document will pay at least as much attention to the absolute costs of running various departments. The nine establishments within the Ministry of Technology and the Atomic Energy Research Establishment at Harwell will thus inevitably excite the interest and the envy of those who work elsewhere. On paper, at least, the AERE is the most lavishly endowed, no doubt because of the cost involved in building and refurbishing equipment associated with nuclear reactors. In 1965-66, the cost of the establishment worked out at $\mathfrak{1 4 . 5 7}$ million, equivalent to $£ 19,663$ for each scientifically qualified member of the staff. In the nine stations transferred to the Ministry of Technology from the old DSIR, the average cost of a year's work by a scientifically qualified researcher worked out at $£ 15,148$. These figures are much greater than those applicable in other kinds of laboratories, some of which are referred to in Table 1.

Table 1. COSTS OF RUNNING BRITISH RESEARCH ESTABLISH. MENTS IN 1964-65 IN $£$ PFR QUALIFIED RESEARCHER

\begin{tabular}{lcccr}
\multicolumn{1}{c}{ Establishment } & Salaries & Equipment & Buildings & Total \\
Min-Tech labs. & 8,096 & 2,660 & 4,167 & 15,148 \\
NIMR & 6,701 & 1,260 & 583 & 8,590 \\
Rothamsted & 4,860 & 542 & 1,219 & 6,888 \\
AERE* & 10,439 & 5,796 & 3,428 & 19,663 \\
& * For $1965-66$. & &
\end{tabular}

The figures in the report which indicate university expenditure on research and development are not comparable with these, chiefly because of the difficulty of deciding how to apportion the cost of buildings and services to the research which is carried on in university departments. It is also important that the cost of salaries attributable to the research in different public laboratories does not reflect great differences in the individual salaries paid to research workers. Although some laboratories seem to pay better salaries than others, the most marked difference between them is the extent to which the efforts of research workers are supported by the efforts of others. Thus the ratio of total staff to scientific staff varies from 4.65 at the National Institute for Medical Research and $3 \cdot 77$ at Rothamsted to 8.22 at the Atomic Energy Research Establishment at Harwell. The Central Veterinary Laboratory at Weybridge boasts of $2 \cdot 6$ technical staff for each researcher, but the record of the university departments is even less cheerful, even when research students are not counted among the academic researchers--the convention followed in the report.

Although the amount of money being spent on running the laboratories has increased absolutely over the years, and although the cost of equipment has often increased quite sharply, it does appear that the greater part of the increasing cost of operating scientific laboratories has been swallowed up by inflation. Table 2 shows the way in which the percentage rates of growth in recent years are almost entirely offset by the percentage increases in each year which must be attributed to inflation.

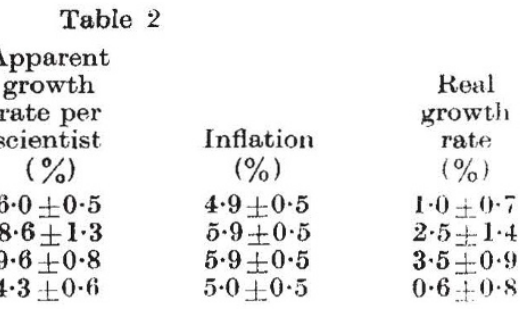

Min-Tech labs.

NIMR

Rothamsted

AERE

$5 \cdot 9 \pm 0 \cdot 5$
$5 \cdot 0+0 \cdot 5$

$0 \cdot 6+0 \cdot 8$

Precisely what implications these figures will have for the development of policy in science it is too soon to know. The report of the survey itself says that. there is a great need to accumulate further information on this and other subjects. Long before that has been done, the British Government may choose to interpret. information like that contained in Table 2 as a proof that, if only government departments are tough enough, even the most powerful laboratories can be made to draw in their horns.

The report will also be followed carefully by those seeking evidence of the trend of university expenditure in the past decade or so. The three university departments covered by the survey seem to have kept successfully ahead of the government laboratories during most of this period. The department of geology included in the survey, for example, increased its staff from 8 to 15 between 1955 and 1964, and the numbers of research students on the books increased from 5 to 14 during the same period. Technical staff increased in numbers even more rapidly, from 5 in 1955 to 18 in 1964. This implies an annual rate of growth of the research force at the laboratory of 10.9 per cent a year, but average salary during the same period increased from $£ 1,051$ per researcher per year to $£ 1,837$ per. researcher per year. These figures include the cost of technical assistance (but research students are counted as researchers). The most rapid increase in th. department's salary bill is attributable to the salaries of technical assistants-a three-fold increase of the labour force was accompanied by a six-fold increase: of salary.

Much the same pattern seems to have been followed at the zoology department at the same university. although this has not grown as quickly in numerical terms. One striking feature of the figures which are provided in the survey is the modesty of the sums available for travel by the academic staff. The zoology department, for example, spent $£ 239$ on the travel of 27 research people in 1955 and $£ 675$ on the travelling expenses of 49 people a decade later. Although the report on sophistication has made no explicit attempt to work out the sophistication of these smaller components of the budget, it is hard to believe that the rates of increase implied by the figures obtained from two university departments can have. allowed the academics concerned to keep pace with the growing cost of travel, let alone with the growing need among research people to attend research conferences in ever more distant places. Academic readers of the report will also be impressed with the comparatively modest scale on which university departments appear to be able to provide themselves with equipment. 